\section{Implementation of public health practices in tribal populations of India: challenges and remedies}

\author{
Saurabh R. Shrivastava, \\ Prateek S. Shrivastava, \\ Jegadeesh Ramasamy \\ Department of Community Medicine, \\ Shri Sathya Sai Medical College \& \\ Research Institute, Ammapettai, India
}

\section{Abstract}

Large inequities in health exist between indigenous and non-indigenous populations worldwide. This health divide has also been demonstrated in India, where indigenous groups are officially classified as scheduled tribes (STs). India has one of the largest tribal populations in the world. Tribal communities in general and primitive tribal groups in particular are highly disease prone and their misery is compounded by poverty, illiteracy, ignorance of causes of diseases, hostile environment, poor sanitation, lack of safe drinking water, blind beliefs, etc. As per the estimates of National Family Health Survey-3 (NFHS-3), the likelihood of having received care from a doctor is lowest for ST mothers (only $32.8 \%$ compared to India of $50.2 \%$ ). While many strategies have been attempted over the years to discuss some of the economic, social, and physical factors preventing tribal population to get access to healthcare services, the ultimate outcome has remained far less than the expectations. Considering that these ST groups are culturally and economically heterogeneous, the methods to tackle their health problems should not only be integrated and multi-fold, but also specific to the individual groups as feasibly as possible. Measures like strengthening of the existing human resources, bringing health services within the reach of remote populations, promotion of health awareness, facilitation of community participation using innovative strategies, bringing about a change in the behavior of health care providers, implementation of measures for the empowerment of ethnic groups by carrying out administrative reforms and finally by ensuring the sustainability of all above recommended measures.

\section{Introduction}

Large inequities in health exist between indigenous and non-indigenous populations worldwide. ${ }^{1}$ This health divide has also been demonstrated in India, ${ }^{2}$ where indigenous groups are officially classified as scheduled tribes (STs). Scheduled tribes are groups of historically disadvantaged people who are descendents of the tribal communities. This group of people did not agree to caste system. Instead, they prefer to dwell deep inside forests as well as mountainous areas of India, far away from the chief part of the society. India has one of the largest tribal populations in the world. The Government of India defined a tribal region based on certain characteristics, ${ }^{3}$ which include (and are not limited to) economically backward communities living in a primitive condition, having a distinct culture, primitive traits, socio-economic backwardness and usually away from the mainstream. The tribal population of the country, as per the 2001 census, is 84.3 million, constituting $8.2 \%$ of the total population with $91.7 \%$ of them living in rural areas and $8.3 \%$ in urban areas. ${ }^{4}$

Tribal communities in general and primitive tribal groups in particular are highly disease prone. The ST groups who were even more isolated from the wider community and who maintained a distinctive cultural identity have been categorized as primitive tribal groups. These have been identified as less acculturated ethnic groups among the tribal population groups and are in need of special programs for their sustainable development and they do not have required access to basic health facilities. They are most exploited, neglected, and highly vulnerable to diseases with high degree of malnutrition, morbidity and mortality. ${ }^{5}$ Their misery is compounded by poverty, illiteracy, ignorance of causes of diseases, hostile environment, poor sanitation, lack of safe drinking water, and blind beliefs, etc.

Although ST are accorded special status under the fifth/sixth schedules of the Indian Constitution, their status on the whole, especially their health, remains unsatisfactory. This paper explores the problems in delivering public health services to the tribal population, and suggests possible recommended measures about the same.

\section{Indian scheduled tribes demography}

The total population of STs according to the 2001 Census is 84.3 million and has increased from 67.8 million in 1991, showing a decadal growth rate of $24.3 \%$. This rate of growth remains higher than the national average of $21.3 \%{ }^{2}$ Scheduled tribes are distributed throughout the nation except Pondicherry, Haryana, Punjab, Chandigarh, and Delhi. Almost 25\% of the Indian tribal live in Madhya Pradesh and Chattisgarh. ${ }^{6}$ Out of the 75 districts with more than $50 \%$ of their population
Correspondence: Saurabh RambihariLal Shrivastava, Department of Community Medicine, Shri Sathya Sai Medical College \& Research Institute, Thiruporur-Guduvancherry main road, Ammapettai, 603108 Kancheepuram, India.

Tel. +91.9884227224 - Fax: .91.044.27440138.

Email: drshrishri2008@gmail.com

Key words: tribal, public health, community participation.

Contributions: SS, conception and design, drafting of the article, review of literature, guarantor; PS, drafting of the article, review of literature, critically revising of the article for important intellectual content; JR, general supervision of the research, overall guidance in writing the manuscript.

Conflict of interests: the authors declare no potential conflict of interests.

Received for publication: 19 December 2012. Revision received: 14 January 2013.

Accepted for publication: 14 January 2013.

This work is licensed under a Creative Commons Attribution 3.0 License (by-nc 3.0).

CCopyright S.R. Shrivastava et al., 2013 Licensee PAGEPress, Italy

Healthcare in Low-resource Settings 2013; 1:e doi:10.4081/hls.2013.e

being composed of STs, 41 districts are from north-east states. ${ }^{6}$

The sex ratio of tribal is more favorable to women than the general population $(972 / 1000$ men vs 927/1000). However, there is a wide variation among the different groups and states (1002 in Orissa to 889 in Goa). ${ }^{4}$ The dependency ratio among tribes is $83.9 \%$ and in the general population is $69 \%{ }^{4}$ Literacy is increasing (47\% in 2001 from $29.6 \%$ in 1991) but still lower than the general population (65\%) and the gap between the literacy rates of STs and the general population has continued almost at the same level of $17-18 \%$ for the last three decades. Almost $65 \%$ women are illiterate against the national figure of $46 \%{ }^{4}$ Dropout rates of tribal students of standard (oneten) have gradually decreased from $85 \%$ in $1990-1991$ to $76.8 \%$ in $2007-2008$. $^{7}$ Around $91 \%$ of the tribal population still lives in rural area as against $72 \%$ for the nation. ${ }^{4}$ The percentage of tribal living below poverty line is $47.3 \%$ in rural and $33.3 \%$ in urban areas, which is higher than the corresponding national figures of $28.3 \%$ and $25.7 \%$, respectively. ${ }^{8,9}$ The average tribal household size is 5.2 and is comparable to the national average of $5.3 .^{4}$ 


\section{Maternal and child health parameters}

There are vast differences in the health status of mothers and children between tribal and non-tribal populations.

Table 1 shows the indicators comparing the maternal and child health, highlighting the under-achievements among the tribes. ${ }^{9,10}$ In a hospital-based, retrospective, reproductive-age mortality study (RAMOS) of tribal women of Bastar region, Chhattisgarh, maternal mortality percentage among tribal women was $85.7 \%$ and was 100\% in the year 2009-2010 and 20102011 which is higher than the national estimates. ${ }^{11}$ Compared to the National Family Health Survey-2 (NFHS-2) survey, ${ }^{9}$ the infant mortality, under-five mortality, and neonatal mortality have decreased: ${ }^{10}$ the proportion of home deliveries is at a standstill. In a retrospective cohort study done in Maharashtra, percentage of still-births in tribal areas (1.96\%) was higher than non-tribal areas (1.47\%). ${ }^{12}$ The total fertility rate (Table 1 ) had shown a slight increase compared to the NFHS-2 survey. Though obstetrics care from a trained provider during delivery is recognized as critical for the reduction of maternal and neonatal mortality, only $17.1 \%$ of births to ST women was assisted by a doctor, compared with $47.4 \%$ of births to women, who do not belong to a scheduled caste, ST, or other backward class group (others).$^{10}$ As per the estimates of NFHS-3, the likelihood of having received care from a doctor is lowest for ST mothers (only $32.8 \%$ compared to India of $50.2 \%)$. The percentage of ST women consuming iron folic acid (IFA) for at least 90 days and who took a drug for intestinal parasites during their pregnancy was only 17.6 and 3.7, respectively. ${ }^{10}$ In a study done in Yeotmal district of Maharashtra, it was concluded that reach of contraceptive services of copper-T $(\mathrm{Cu}-\mathrm{T})$ needs to be improved in tribal areas. ${ }^{13}$

Among ST children who suffered from diarrhoea in the two weeks preceding the survey, only $29.3 \%$ of them did not receive any treatment at all. Based on information obtained from a vaccination card or reported by the mother (either source), only $31.3 \%$ of ST children were found to be fully vaccinated as compared to $53.8 \%$ belonging to others. Among ST children, $49.9 \%$ received services at an anganwadi centre. ${ }^{10}$

\section{Other public health problems among tribes}

Compared to national averages, STs have higher mortality rates, ${ }^{14}$ and experience a greater prevalence of tuberculosis,,${ }^{15}$ leprosy, ${ }^{16}$ under-nutrition, ${ }^{10,17}$ visual impairment from avoidable causes of blindness including the outcome of surgeries, ${ }^{18,19}$ and high anaemia levels..$^{20-21,22}$ These groups are also exposed to higher risks of inadequate food intake,,$^{23}$ poor hygiene,$^{24}$ and tobacco and alcohol consumption, ${ }^{25,26}$ as well as lower access to health care. ${ }^{27-30}$ In a community-based cross-sectional study carried out in the tribal population of randomly selected villages of Jabalpur district, it was observed that though $88 \%$ of the respondents felt modern medicine was the best remedy for sexually transmitted infections (STI), only a few of them actually used medical treatment while suffering from an STI. ${ }^{31}$

Northeast India is known for the demographic heterogeneity of its tribal population, and it has a very high prevalence of hepatitis $\mathrm{C}$ virus infection and their associated risk factors. ${ }^{32}$ High sero-prevalence of certain bacterial and viral infections has been observed among Irula and Kolli hills tribes of Tamil Nadu. ${ }^{33,34}$ Intestinal helminthiasis and skin infections such as tinea and scabies are widely prevalent among tribal children. ${ }^{35}$ Sickle cell trait prevalence varies from 0.5 to $45 \%$, and disease prevalence is around $10 \%{ }^{36}$

\section{Public health infrastructure}

Accessibility is one of the principles of Health for All stated in Alma Ata Declaration on primary health care but still, due lack of universal access, equality in health status cannot be assured. Moreover, because there are other important social determinants of population health and its distribution, even with the increasing catchment of tertiary health care facilities, use of primary health care is low due to costs, attitude of health provider as well as place of facilities, etc. Tribal development strategies need to be more human-centred with health at its centre. The conventional, bureaucratic approach of looking at health issues for tribal in a sectoral, compartmentalized way can have little impact on achieving health goals.

While many strategies have attempted to address some of the economic, social, physical factors and barriers contributing to poor maternal health outcomes, women's use of maternal health services is often influenced by perceived socio-cultural, economic, and health system factors operating at the community, household, and individual level as well as within the larger social and political environments and health care infrastructure. These include inequitable distribution of facilities and/or infrastructure for primary healthcare and maternal healthcare services, inadequate referral services and overburdened healthcare facilities..$^{37,38}$ Although in tribal areas the population norms for establishment of primary health centers and sub-centers is for every 20,000 and 3000 population respectively, health care is not available to the majority of the tribal. ${ }^{39}$ This is due to multiple factors, namey lack of accessibility to health facilities; ${ }^{40}$ non-availability of health staff in the health centers; poor quality of services offered (non-availability of essential drugs and equipments, lack of proper building facilities); lack of transport and communication facilities; traditional practices and superstitions (local beliefs, customs, and practices); poverty and financial constraints (the majority of healthcare services is theoretically free of cost, but indirect and informal payments, such as travel cost to and from the government facility, leaving work to seek care, and paying for prescribed medicines, exist); logistics barriers from the healthcare providers side; waiting time at the health center and timings of the facilities. All these factors in multiple ways have obstructed accessibility of healthcare services..$^{40-42}$

Table 1. Maternal and child health indicators among tribes and others. ${ }^{9,10}$

\begin{tabular}{lccc} 
Indicators & & ST & Others \\
& NFHS-2 & NFHS-3 & NFHS-3 \\
Median age at marriage (years) & 15.8 & 16.3 & 18.1 \\
Awareness of legal age for marriage (\%) & 7.5 & - & 22 \\
\hline Total fertility rate & 3.06 & 3.12 & 2.68 \\
Median age at first childbirth (years) & 18.8 & 19.1 & 20.6 \\
\hline Proportion of pregnancies with no antenatal checkups (\%) & 43.1 & 37.8 & 22.8 \\
Home deliveries (\%) & 81.8 & 82.3 & 49 \\
\hline Infant mortality rate/1000 live births & 84.2 & 62.1 & 57 \\
Exclusive breast-feeding (median) (months) & 2.9 & 3.1 & 1.9 \\
\hline Completion of primary immunization (\%) & 26 & 31.3 & 53.8 \\
No. vaccination (\%) & - & 11.5 & 4.3
\end{tabular}

ST, scheduled tribes; NFHS-2, National Family Health Survey-2; NFHS-3, National Family Health Survey-3. 


\section{Recommended measures}

As discussed earlier, STs in India are demographically, culturally and economically heterogeneous, varying widely in terms of their population size, language, and the nature of their interactions with the rest of society. ${ }^{43,44}$ Hence, the methods to tackle their health problems should not only be integrated and multi-fold, but also specific to the individual groups as feasibly as possible. In the following, elements and strategies which should be considered as an essential element of the comprehensive approach for the wellbeing of tribal populations are discussed.

\section{Strengthening of the existing human resources}

One of the major problems in delivering health care to the tribal is shortage of staff. Doctors and paramedical workers from the general population are reluctant to work in backward tribal areas. Furthermore, medical staff hailing from the tribal communities, who has a better understanding about the needs of their people and who may be more willing to work in such areas is not enough.

As for March 2010, undue delays in recruitment resulted in vacancies even in available posts at health centers. Over $34 \%$ of male health workers, $38 \%$ of radiographers, $16 \%$ of laboratory technicians, $31 \%$ of specialists, $20 \%$ of pharmacists and $20.7 \%$ of the sanctioned posts of doctors were lying vacant. ${ }^{45,46}$ Though there is a statutory provision of $7.5 \%$ reservation for tribal in medical education, apparently either the enforcement of this policy is not strictly done or takers from the tribal for these seats are not enough. It is proposed that the proportion of distribution of all these reserved seats should be worked out according to the proportion of the individual clans of tribal.

The situation is worse among other cadres of health workers. On the one hand, as such, the number of available paramedic education institutions is very small compared to the needs of the country. Only 13,000 auxiliary nurse midwives (ANMs) are graduating every year. ${ }^{47} \mathrm{~A}$ phenomenal increase is required in this area, which is the purview of general policy. Within this area, a parallel sponsorship with educational opportunities has to be developed to cater for the needs of the tribal population. To tackle the acute shortage of medical doctors, Indian Government has planned to make its undergraduate Bachelor of Medicine and Bachelor of Surgery (MBBS) course sixand-a-half years long, instead of the present five-and-a-half years that would make a one- year rural posting compulsory for all MBBS students before they can become doctors. ${ }^{46}$ Also, with a purpose to churn out more doctors, the union health ministry has increased postgraduate seats by $85 \%$ and undergraduate seats by $35 \%$ in various medical colleges of the country over the last three years. ${ }^{48}$ In addition, the Medical Council of India (MCI) has also cleared a three-and-a-half-year long medical course (Bachelor of Science in Community Health) which will be open to anybody after class $12 .{ }^{49}$

\section{Bringing health services to remote populations}

While medical camps have often been conducted in the past, different stakeholders have stressed on the need for either state-sponsored or non-governmental organizations (NGOs), sponsored mobile medical camps to reach remote tribal populations. Outsourcing of these services to NGOs and medical colleges may prove to be an efficient option if availability of drugs, diagnostic facilities and vehicles remains assured and consistent. Population can be drawn to these camps through door-todoor canvassing by Accredited Social Health Activists (ASHA) and ANM, as well as loudspeaker announcements, banners and pamphlets. Provision of emergency transportation to take tribal pregnant women to health facilities for obstetrical care should be ensured. While not all hamlets have access to tarred roads, the emergency ambulance services should reach the nearest motorable point to pick up patients in all tribal regions. Janani Suraksha Yojana is a safe motherhood intervention being implemented with the goal of reducing maternal and neo-natal mortality by promoting institutional delivery among the poor pregnant women. To encourage institutional deliveries among tribal groups, stringent enforcement and implementation of Janani Suraksha Yojana should be done. ${ }^{50}$

\section{Promotion of awareness about health issues}

Promotion of awareness about health-related issues is the first step towards improving health outcomes. However, while public health programs have often conducted information, education and communication (IEC) campaigns - such as stressing the importance of hand washing, regular antenatal check-ups, institutional deliveries, immunization, etc. they have had little impact. In order to have a significant impact on tribal masses, all the messages should be culturally appropriate and professionally crafted to markedly improve the content and quality of health messages and pre-tested for greatest impact at specific tribal groups.

In Rajasthan, health messages were most commonly disseminated using live performances by drummers, dancers, folk musicians, magicians, puppeteers, etc. to appeal to tribal populations. Similarly, in Tamil Nadu, in addition to posters, hoardings, bus boards, and personalized letters of communication for the literate members of a family, radio jingles and video broadcasts featuring popular film stars were found to be effective means for disseminating health messages to the state's tribal people. Even in developed nations culturally appropriate technology was employed for targeting the native youth of tribal populations. ${ }^{51}$ Community-based participatory research (CBPR) which is conducted as an equal partnership between traditionally trained experts and members of a community has been hailed as an alternative approach which emphasizes co-sharing, mutual benefit, and community capacity building. ${ }^{52}$

\section{Facilitating tribal community participation}

Women from the tribal localities can be recruited as ANMs and then trained to bring health care closer to tribal settlements. Also, as tribal populations find it difficult to navigate through the complexities of medical facilities, government in collaboration with local NGOs can arrange for counselors who are from tribal communities themselves and then can be placed at district hospitals to guide patients, explain doctors' prescriptions, help patients take advantage of welfare schemes and counsel them on preventive and promotive health behaviors. These counselors can also pay weekly visits to tribal hamlets to raise awareness about health issues and promote healthy behaviors. In Karnataka, citizens helpdesks have been established to offer round-the-clock assistance to tribal and other vulnerable groups in selected district and taluk level hospitals. These helpdesks also address complaints by mediating between consumers and service providers. ${ }^{53}$

\section{Changing the behavior of health care providers}

To help tribal people at medical facilities, the obligation is to change their insensitive and discriminatory behavior towards poor and dis- 
advantaged groups. This change in behavior is desired not only from paramedic and lower staff but also from the doctors. This can be achieved by organizing campaign to instill patientfriendly behavior among health care providers. Simultaneously, there should be a mechanism to get feedback from tribal people based on which corrective measures should be taken.

\section{Empowerment of the tribal population}

Nutrition and education are basic accessories needed for the progress of any community. A closely knit Public Distribution System (PDS) as witnessed in Anthyodaya Anna scheme has to be developed nationwide, covering every interior pocket of the tribal areas, with a well-supported supply network. Under this scheme, the poorest of the poor were supported by providing them with $35 \mathrm{~kg}$ of rice and wheat at Rs. 2 per kg. ${ }^{54}$

In the same vein, schooling and education have to be developed fully utilizing the help of anthropologists and non-governmental organizations to inculcate the habit of universal education at the primary, middle, and higher secondary levels. Initiatives to distribute educational and related items free of cost along with supplementary nutrition have also been found successful in states like Tamil Nadu. To recognize the achievements of the tribal population, the Ministry of Tribal Affairs instituted the National Tribal Awards from the year 2008 for the Best Janjatiya achiever. Such awards and monetary benefits should be extended in future for the best performing grass-root level health workers which will serve as a source of continuous motivation. Provision of health insurance should be extended to the STs for prompt use of healthcare services by them without undue debt. ${ }^{55}$

Tribal Cooperative Marketing and Development Federation of India Ltd. (TRIFED) is a welcome sign as it provides marketing help and remunerative prices to STs for collection of minor forest production and surplus agricultural production to protect them from exploitative private traders and middlemen. ${ }^{56}$

\section{Administrative reforms approach}

The utilization of any social services, including health services, has never been equitably distributed throughout society. People with access to the facilities are generally found to make greater use of them than people who have neither knowledge nor access to the facilities. Though health is a state subject, the Centre has been given the authority of giving directions to the State governments [Article 339 (2) of the fifth schedule in the interest of the tribal population], which should be used to direct the state governments to ensure provision of separate tribal sub-plans based on the percentage of tribal as recommended by the Ministry of Tribal Affairs. In a cohort of births examined in Gujarat, it was concluded that for sustaining the momentum of reduced neonatal mortality there is a need of long-term policy intervention to promote better living standards and better reproductive health. ${ }^{57}$ Racial and Ethnic Approaches to Community Health (REACH) is an initiative promoted by the Centers for Disease Control and Prevention's (CDC), which strives to eliminate racial and ethnic disparities in health. It is a communitybased, participatory approach to identify, develop and disseminate effective strategies for addressing health disparities across a wide range of health priority areas such as cardiovascular disease, diabetes, breast and cervical cancer, infant mortality, asthma, immunization, and obesity. ${ }^{58}$ Similar strategies/programs customized to the local tribal population can be devised to eliminate caste-based disparities in health. While most innovations have included the provision of free medical services to poor tribal populations, a few pilots have sought to ease the financial burden of inpatient care on these groups as well. In Tamil Nadu, bed grant scheme was implemented under financial assistance of World Bank, in partnership with NGOs for the provision of free inpatient care to tribal populations. All costs pertaining to minor ailments and surgeries are reimbursed by the project.

\section{Ensuring sustainability}

In authors' opinion, though many of the above suggested methods are not entirely new ones and have been tried with success in vast sections of non-tribal areas, the administrative skills and organizational capabilities need to be tuned up according to the tribal needs. Politically-sustained and administrative commitment is what we currently need to have a long-term and comprehensive impact on the health status of tribal populations.

\section{References}

1. Cunningham C. Health of indigenous peoples. Brit Med J 2010;340:1840.

2. Subramanian SV, Smith GD, Subramanyam M. Indigenous health and socioeconomic status in India. PLoS Med 2006;3:1794-804.

3. Angra SK, Murthy GV, Gupta SK, Angra V. Cataract related blindness in India and its social implications. Indian $\mathrm{J}$ Med Res 1997;106:312-24.

4. Registrar General of India. Census of India, 2001. New Dehli: Registrar General of India ed.; 2001.

5. Balgir RS. Dimensions of rural tribal health, nutritional status of Kondh tribe and tribal welfare in Orissa: a biotechnological approach. In: BN Bandodkar College of Science, ed. Proceedings of the UGC sponsored National Conference on Human Health and Nutrition: a Biotechnological Approach, 2004 Dec 1213, Thane, India. Thane: BN Bandodkar College of Science ed.; 2004. pp 47-57.

6. Draft national policy on tribals, 2005. New Delhi: Ministry of Tribal Affairs, Government of India ed.; 2005.

7. Tables of statistics for school education; 2007-2008. Available from: http://www.educationforallinindia.com/selected-education-statistics-2007-08-MHRD.pdf

8. Planning Commission, Government of India. Eleventh Five Year Plan. New Delhi: Planning Commission, Government of India ed.; 2008.

9. International Institute for Population Sciences, Macro International. National Family Health Survey (NFHS-2), 1998-99. Mumbai, Claverton: IIPS, Macro International ed.; 2000.

10. International Institute for Population Sciences, Macro International. National Family Health Survey (NFHS-3), 2005-06. Vol. I. Mumbai, Claverton: IIPS, Macro International ed.; 2007.

11. Chauhan P, Chauhan VK, Shrivastava P. Maternal mortality among tribal women at a tertiary level of care in Bastar, Chhattisgarh. Glob J Health Sci 2012;4:132-41.

12. Doke PP, Karantaki MV, Deshpande SR. Adverse pregnancy outcomes in rural Maharashtra, India (2008-09): a retrospective cohort study. BMC Public Health 2012;12:543.

13. Ambadekar NN, Rathod KZ, Zodpey SP. Health care delivery practices in the rural part of the Yavatmal district regarding IUD insertion. Indian $\mathrm{J}$ Public Health 2010;54:201-4.

14. Subramanian SV, Nandy S, Irving M, et al. The mortality divide in India: the differential contributions of gender, caste, and standard of living across the life course. Am J Public Health 2006;96:818-25.

15. Kaulagekar A, Radkar A. Social status makes a difference: tuberculosis scenario during National Family Health Survey-2. Indian J Tuberc 2007;54:17-23. 
16. Kumar AS, Kumar S, Abraham S, Rao PS. Leprosy among tribal population of Chhattisgarh state, India. Indian J Lepr 2011;83:23-9.

17. Bawdekar M, Ladusingh L. Contextual correlates of child malnutrition in rural Maharashtra. J Biosoc Sci 2008;40:771-86.

18. Dhake PV, Dole K, Khandekar R, Deshpande M. Prevalence and causes of avoidable blindness and severe visual impairment in a tribal district of Maharashtra, India. Oman J Ophthalmol 2011;4:129-34.

19. Khanna RC, Pallerla SR, Eeda SS, et al. Population based outcomes of cataract surgery in three tribal areas of Andhra Pradesh, India: risk factors for poor outcomes. PLoS One 2012;7:e35701.

20. Bharati P, Som S, Chakrabarty S, et al. Prevalence of anemia and its determinants among non pregnant and pregnant women in India. Asia Pac J Public Health 2008;20:347-59.

21. Nayar KR. Social exclusion, caste \& health: a review based on the social determinants framework. Indian $\mathrm{J}$ Med Res 2007;126:355-63.

22. De M, Halder A, Chakraborty T, et al. Incidence of anemia and effect of nutritional supplementation on women in rural and tribal populations of eastern and northeastern India. Hematology 2011;16:190-2.

23. Ghosh R, Bharati P. Women's status and health of two ethnic groups inhabiting a peri-urban habitat of Kolkata City, India: a micro-level study. Health Care Women In 2005;26:194-211.

24. Basu SK. A health profile of tribal India. Health Millions 1994;2:12-4.

25. Neufeld KJ, Peters DH, Rani M, et al. Regular use of alcohol and tobacco in India and its association with age, gender, and poverty. Drug Alcohol Depen 2005;77:28391.

26. Mohindra KS, Narayana D, Anushreedha SS, Haddad S. Alcohol use and its consequences in South India: views from a marginalised tribal population. Drug Alcohol Depen 2011;117:70-3.

27. Nanda S, Tripathy M. Reproductive morbidity, treatment seeking behaviour and fertility: a study of scheduled caste and tribe women. J Hum Ecol 2005;18:77-83.

28. Meher R. Livelihood, poverty and morbidity: a study on health and socio-economic status of the tribal population in Orissa. J Health Manag 2007;9:343-67.

29. Dolla CK, Meshram P, Verma A, et al. Health and morbidity profile of Bharias - a primitive tribe of Madhya Pradesh. J Hum Ecol 2006;19:139-41.

30. Ray SK, Basu SS, Basu AK. An assessment of rural health care delivery system in some areas of West Bengal-an overview. Indian J Public Health 2011;55:70-80.

31. Rao VG, Saha KB, Bhat J, et al. Exploring knowledge and health seeking behaviour related to sexually transmitted infections among the tribal population of Madhya Pradesh, central India. J Biosoc Sci 2012;44:625-9.

32. Medhi S, Goswami B, Das AK, et al. New insights into hepatitis $\mathrm{C}$ virus infection in the tribal-dominant part of Northeast India. Arch Virol 2012;157:2083-93.

33. Gnanasekaran A, Paramasivam R, Mohan $\mathrm{K}$, et al. Seroprevalence of certain bacterial and viral infections among the Irula tribal population of Marakkanam, Tamil Nadu state, India. Prim Health Care Res Dev 2012:1-7.

34. Kalaivani V, Rajendran P, Thyagarajan SP, et al. The seroprevalence of hepatitis $B$ and $\mathrm{C}$ viruses and the associated risk factors in the Kolli hills tribal population of Tamil Nadu. Biomedicine 2001;21:7-13.

35. Chhotray GP. Health status of primitive tribes of Orissa. ICMR Bull 2003;33:1-6.

36. Sahu T, Sahani NC, Das S, Sahu SK. Sickle cell anemia in tribal children of Gajapati district in Orissa. Indian $\mathrm{J}$ Community Med 2003;28:180-3.

37. Griffiths P, Stephenson R. Understanding users' perspectives of barriers to maternal health care in Maharashtra, India. J Biosoc Sci 2001;33:339-59.

38. Ram F, Singh A. Is antenatal care effective in improving maternal health in rural Uttar Pradesh? Evidence from a district level household survey. J Biosoc Sci 2006;38:433-48.

39. Indian Public Health Standards (IPHS) guidelines for primary health centers. New Dehli: Directorate General of Health Services, Ministry of Health and Family Welfare, Government of India ed.; 2012. Available from: http://mohfw.nic.in/ NRHM/IPHS_Revised_Guidlenes_2012/Pri may_Health_Centres.pdf

40. Saha PK. The status of family welfare services in tribal areas: highlights of the evaluation process. Indian J Community Med 2003;28:141-4.

41. Levesque JF, Haddad S, Narayana D, Fournier P. Outpatient care utilization in urban Kerala, India. Health Policy Plann 2006;21:289-301.

42. Levesque JF, Haddad S, Narayana D, Fournier P. Affording what's free and paying for choice: comparing the cost of public and private hospitalizations in urban Kerala. Int J Health Plan M 2007;22:159-74.

43. Xaxa V. Protective discrimination: why scheduled tribes lag behind scheduled castes. Econ Polit Weekly 2001;21:2765-72.

44. Kakkoth $\mathrm{S}$. The primitive tribal groups of kerala: a situational appraisal. Stud Tribes
Tribals 2005;3:47-55.

45. Rural health statistics in India; 2010. Available from: http://nrhm-mis.nic.in/ UI/RHS/RHS\%202010/Rural\%20Health\%20 Statistics\%202010.htm

46. Times News Network. Govt mulls six-anda-half year MBBS with one-year rural stint. In: The Times of India, section Times Nation (col. 1), 06/02/2012.

47. Ministry of Health and Family Welfare. National rural health mission. Strengthening of public health infrastructure. New Dehli: MOHFW ed.; 2005.

48. Times News Network. Norms relaxed to increase medical seats. In: The Times of India, section Times City (col. 2), 29/09/ 2012.

49. Kounteya Sinha. MCI clears 3-and-a-halfyr med course. In: The Times of India, section Times Nation (col. 3), 24/09/2012.

50. Janani Suraksha Yojana. Guidelines for implementation; 2006. Available from: http://www.mohfw.nic.in/NRHM/RCH/guid elines/JSY_guidelines_09_06.pdf

51. Rushing CS, Stephens D. Tribal recommendations for designing culturally appropriate technology based sexual health interventions targeting Native youth in the Pacific Northwest. Am Indian Alaska Nat 2012;19:76-101.

52. Wallerstein N, Duran B. Community-based participatory research contributions to intervention research: the intersection of science and practice to improve health equity. Am J Public Health 2010;100:S40-6.

53. Karnataka health system development and reform project national rural health mission. Operational guidelines for citizen help desk under public private partnership; 2009. Available from: http://stg2. kar.nic.in/healthnew/KSHRDP/PDF/PPP/0 perational\%20Guidelines\%20for\%20Citize n\%20Help\%20Desk.pdf

54. Antyodaya Anna Yojana; 2000. Available from: http://www.karmayog.org/publicdistributionsystem/publicdistributionsystem_2619.htm

55. Friedsam D, Haug G, Rust M, Lake A. Tribal benefits counseling program: expanding health care opportunities for tribal members. Am J Public Health 2003;93:1634-6.

56. Tribal cooperative marketing development federation of India limited, 2004. Available from: http://tribal.gov.in/ indexl.asp?linkid $=359$ \&langid $=1$

57. Kutty RV, Shah P, Modi D, et al. Reducing neonatal mortality in Jhagadia Block, Gujarat: we need to go beyond promoting hospital deliveries. J Trop Pediatrics [In press].

58. Racial and ethnic approaches to community health (REACH). Atlanta: Centers for Disease Control and Prevention ed.; 2012. Available from: http://www.cdc.gov/reach/ 